\title{
JAUNESNIOJO MOKYKLINIO AMŽIAUS BERNIUKŲ ŠOKLUMO RODIKLIŲ POKYČIAI
}

\author{
Eduardas Rudas ${ }^{1}$, Albertas Skurvydas ${ }^{1}$, Dalia Mickevičiené ${ }^{1}$, \\ Vaidas Mickevičius ${ }^{2}$, Tomas Juraitis ${ }^{1}$ \\ Lietuvos kūno kultūros akademija ${ }^{1}$, Kauno technikos kolegija ${ }^{2}$, Kaunas, Lietuva
}

Eduardas Rudas. Kūno kultūros magistras. Lietuvos kūno kultūros akademijos biologijos krypties doktorantas. Mokslinių tyrimų kryptis — jaunesniojo mokyklinio amžiaus vaikų šoklumo judesių kaita.

\section{SANTRAUKA}

Tyrimo tikslas — nustatyti ir palyginti jaunesniojo mokyklinio amžiaus berniuku šoklumo rodikliu kaita, skirtingais krūviais ugdant šokluma du mènesius.

Šiame straipsnyje palyginta jaunesniojo mokyklinio amžiaus sveiku, normaliai išsivysčiusiu ketvirtu klasiu(9-11 m.) berniuku šoklumo kaita, ugdant šokluma skirtingais krūviais aštuonias savaites. Buvo tiriami 49 ketvirtu klasiu berniukai. Tirtos dvi eksperimentinès grupès ir viena kontrolinè. Eksperimentinèse grupése buvo 32 moksleiviai, po 16 kiekvienoje. Pirmos eksperimentinès grupés tiriamuju $(n=16)$ amžius - 10,0 $\pm 0,7$ m., kūno masé $-33,1 \pm 5,1 \mathrm{~kg}$, $\bar{u}$ gis - 143,0 \pm 6,5 cm, antros ( $n=16)$ - amžius - 10,3 \pm 0,4 m., kūno masé - 34,8 $\pm 6,7 \mathrm{~kg}, \bar{u}$ gis - 143,6 \pm 7,2 cm, kontrolinès $(n=17)$ - amžius - 10,4 \pm 0,5 m., kūno mase $-34,8 \pm 6,8 \mathrm{~kg}$, ügis $-145,1 \pm 6,8 \mathrm{~cm}$. Atlikti trys tyrimai.

Eksperimentinèse grupése šoklumas ugdytas per 15 pratybu, kurios truko beveik du ménesius po du kartus per savaitę. Kontroline grupé buvo testuojama tik du kartus — tyrimo pradžioje ir po 8 savaičiu. Visose grupése kiekvienu pratybu metu po neintensyvios 10 min pramankštos buvo atliekami vertikalūs šuoliai maksimaliai pašokant. Pirmoje eksperimentineje grupejje tiriamieji per kiekvienas pratybas atliko po 50 šuoliu kas $30 \mathrm{~s}$, antroje - po tokios pat pramankštos buvo atliekami 25 šuoliai kas 30 s per kiekvienas pratybas. Kontrolinëje grupejje po tokios pat pramankštos buvo atliekami 25 šuoliai kas 30 s. Visose grupèse rekomenduojama pašokti kiek galima aukščiau. Šuoliu aukščiui nustatyti buvo naudojama kontaktinè platforma, sujungta su elektroniniu šuolio aukščio ir atsispyrimo laiko matuokliu. Vertikalūs šuoliai aukštyn atliekami amortizuojamai pritūpiant iki 90 (hp 90) kampo per kelius (kampas kontroliuojamas stebint), tiriamojo rankos — ant juosmens. Tiriamuju šuoliai fiksuojami asmeniniame protokole. Rezultatai apdoroti matematines statistikos metodais.

Berniuku šoklumas abiejose eksperimentinèse grupèse pagerèjo reikšmingai, tačiau berniuku, atlikusiu daugiau šuoliu, rezultatai pagerèjo reikšmingai $(p<0,05)$, palyginti su mažiau šuoliu atlikusiu tiriamuju. Kontrolinès grupès berniuku šuoliu rezultatu skirtumas nereikšmingas. Dèl pratybu moksleiviu šoklumo vidurkiu rezultatu sklaida padidejjo ir kur kas labiau grupès, kuri atliko daugiau šuoliu. Be to, nustatyta, kad nèra reikšmingo koreliacinio ryšio tarp šuoliu aukščio ugdymo pratybu pradžioje ir pabaigoje (po 15 pratybu).

Raktažodžiai: šuoliai, šoklumo technika, raumenu nuovargis.

\section{IVADAS}

$\breve{S}$ oklumas priklauso nuo daugelio specifiniu griaučių raumenų funkcinių savybių, kompozicijos, t. y. nuo greitų ir lètų raumeninių skaidulu procentinès sudèties, nuo elastinių ir mioelektrinių raumenų savybių, i kurias pirmiausia dėmesi atkreipé J. V. Verchošanskis dar 1970 metais, panaudojimo amortizacinių pratimų metu.
Šoklumas ir greitumas — vyraujantys kompleksiniai motoriniai ivvairių šakų sportininkų gebėjimai (Bosco et al., 1983 a, b; Balsom et al., 1992; Skurvydas ir kt., 1995). Raumenų susitraukimo veiksmingumas priklauso nuo daugelio fiziologinių, biocheminių veiksnių (Bosco, Komi, 1979; Fitts et al., 1991; Enoka, 1994), kuriuos lemia 
ne tik motorinès sistemos augimas ir brendimas (Belanger, McComas, 1989; Malina, Bouchard, 1991), bet ir treniruočiu kiekis (Korman et al., 2003), krūvio apimtis (Bobbert, 1990; Viitasalo et al., 1998; Skurvydas, 1991; Hakkinen, 1994; Mamkus, 1998; Stanislovaitis, 1998). Šoklumas gerẻja organizmui augant ir bręstant, todèl labai reikšmingas laikotarpis yra paauglystė (Malina, Bouchard, 1991; Spirduso, 1995). Šis tarpsnis sutampa su didejjančiu motoriniu aktyvumu, taip pat spartesniu motorikos lavejjimu natūralaus brendimo laikotarpiu (Astrand, Rodahl, 1986; Jaščaninas ir kt., 1989; Malina, Bouchard, 1991; Glenmark et al., 1992; Kraemer, Fleck, 1993). Literatūroje aptinkame duomenu, kad jaunas organizmas lengvai prisitaiko prie pratybų krūvių (Malina, Bouchard, 1991; Komi, 1992; Kraemer, Fleck, 1993), tačiau dar neaišku, kokie krūviai, jų struktūra, apimtis ir intensyvumas turètu būti optimalūs, t. y. skatintu, o ne slopintu natūralaus augimo ir brendimo tempus. Tinkamiausias amžius greitumui ugdyti - 9-13 gyvenimo metai (Karoblis, 1999). Kai kuriais tyrimų duomenimis, ilgai trunkantys krūviai gali lemti greitai susitraukiančių (greitujų) raumeninių skaidulų transformavimąsi į lètai susitraukiančias (lètąsias) (McDoagh, Davies, 1984; Booth, Thomason, 1991; Salmons, 1994). Ugdant šoklumą turètu pagerèti greitumo ir raumenu galingumo rodikliai. Sporto pedagogai ir mokslininkai, remdamiesi organizmo adaptacijos dėsningumais, taiko keletą pagrindinių sporto treniruotės krūvio planavimo sistemų kurios skiriasi krūvių pasiskirstymu ir jų atlikimo specifika (Skurvydas, 1991; Komi, 1992; Enoka, 1994; Wilmore, Costill, 1994). Neaišku, kaip šoklumą ugdantys krūviai, kurie trunka du mėnesius, lemia jaunesniojo mokyklinio amžiaus moksleivių šoklumą.

Tyrimo tikslas - nustatyti ir palyginti jaunesniojo mokyklinio amžiaus (9-11 metų) berniuku šoklumo kaita, skirtingais krūviais ugdant šoklumą du mènesius.

Hipotezė: remdamiesi organizmo adaptacijos prie fizinių krūvių biologiniais dèsningumais (Bosco et al., 1984; Balsom et al., 1992; Glenmark et al., 1992; Komi, 1992), darytume prielaida, kad 8 savaites šokluma ugdantys krūviai gerins šoklumo rodiklius, o didesni krūviai labiau paveiks šuoliu rezultatus.

\section{TYRIMO METODAI IR ORGANIZAVIMAS}

Tiriamieji. Nustatant berniukų šoklumo kaitą buvo tiriami Palemono vidurinès mokyklos normaliai išsivystę, sveiki 9-11 metu 49 berniukai. Ugdant berniukų šoklumą kiekvienos eksperimentinès grupès tiriamieji (po 16 berniuku kiekvienoje) atliko po 50 ir 25 šuolius: BE-50 - berniuku eksperimentinè grupé, atlikusi po 50 šuolių per kiekvienas pratybas; BE-25 —po 25 šuolius per kiekvienas pratybas. Kontrolinejje berniuku grupèje (BK-25) - po 25 šuolius per kiekvienas pratybas. Ją sudare 17 ketvirtos klasės moksleiviu, kurių amžius, ūgis ir svoris nurodytas lentelèje. Visi jie - ketvirtos klasès mokiniai.

Šoklumo testavimas. Vienkartiniai vertikalūs šuoliai buvo fiksuojami naudojant Lietuvos kūno kultūros akademijos Žmogaus motorikos laboratorijoje aprobuotus metodus (Mamkus, 1998; Stanislovaitis, 1998). Šuoliams matuoti buvo naudojama kontaktinè platforma $60 \times 60 \mathrm{~cm}$, laidais sujungta su elektroniniu šuolio aukščio ir atsispyrimo laiko matuokliu. Šuolio aukštis buvo nustatomas pagal polèkio fazès trukmę, kurią tiriamasis išbūna ore pašokęs. Polėkio trukmè perskaičiuojama i šuolio aukšti naudojant formulę (Bosco et al., $1983 \mathrm{a}, \mathrm{b})$ :

$$
h=\frac{g \times t_{p}^{2}}{8}=1,22625 \times t_{p}^{2},
$$

čia: h — šuolio aukštis (m); g — laisvojo kritimo pagreitis $\left(9,80665 \mathrm{~m} / \mathrm{s}^{2}\right) ; \mathrm{t}_{\mathrm{p}}$ - polèkio trukmè (s).

Vertikalūs šuoliai aukštyn atliekami amortizuojamai pritūpiant iki $90^{\circ}$ (hp 90) kampo per kelius (kampas kontroliuojamas stebint), tiriamuju rankos - ant juosmens.

Tyrimo organizavimas. Eksperimentinių grupių moksleiviai ugde šoklumą 8 savaites. Du kartus per savaitę, pirmoje dienos puséje, iki pietų. Kontrolinè grupé buvo testuojama tik du kartus - pradžioje tyrimo ir po 8 savaičių. Tiriamieji po 10 min neintensyvios pramankštos (tempimo pratimų, lèto bėgimo (pulsas bėgimo pabaigoje - iki 110-120 tvinksniu per minute), lengvu šuoliuku) ant kontrolinės platformos atliko vertikalius šuolius, amortizuojamai pritūpdami iki 90 laipsnių per kelių sąnarius. Rankos - ant

\begin{tabular}{|c|c|c|c|}
\hline Grupès & Amžius, m. & Ūgis, cm & Svoris, kg \\
\hline BE-50 & $10,0 \pm 0,7$ & $143,0 \pm 6,5$ & $33,1 \pm 5,1$ \\
\hline BE-25 & $10,3 \pm 0,4$ & $143,6 \pm 7,2$ & $34,8 \pm 6,7$ \\
\hline BK-25 & $10,4 \pm 0,5$ & $145,1 \pm 6,8$ & $34,8 \pm 6,8$ \\
\hline
\end{tabular}


juosmens. BE-50 grupès tiriamieji per du mènesius 15 pratybu metu (po 2 per savaitę) atliko po 50 šuolių kas 30 s maksimaliai pašokdami, BE-25 grupè per du mènesius - 15 pratybų (po 2 per savaitę) po 25 šuolius kas 30 s maksimaliai pašokdami, BK-25 grupè — po 25 šuolius kas $30 \mathrm{~s}$ maksimaliai pašokdami tyrimo pradžioje ir po 8 savaičių. Remiantis C. Bosco ir P. Komi (1979) metodika, buvo apskaičiuojamas vertikalaus šuolio aukštis (h). Kiekvienas moksleivis atliko po 50 vertikalių šuolių kiekvieną pratybų dieną. Buvo nustatomi 10 pirmų šuolių vidurkiai. Rekomenduojama pašokti kiek įmanoma aukščiau, stengiantis pagerinti asmenini rezultatą. Vertikalių šuolių aukštyn rezultatai buvo fiksuojami užrašant i tiriamojo asmenini protokolą.

Matematinè statistika. Vertikalių šuolių rezultatai apdoroti matematinès statistikos metodais apskaičiuojant:

- aritmetini vidurki;

- vidutini kvadratini nuokrypi;
- procentinę rezultatų kaitą;

- skirtumo tarp aritmetinių vidurkių reikšmingumą pagal dvipusį Studento $t$ kriterijų (aritmetiniu vidurkių skirtumo reikšmingumo lygmuo buvo laikomas svarbiu, kai paklaida (p $<0,05)$ mažesnè nei 5\%;

- ryšį tarp rodiklių. Taikytas Pirsono koreliacijos koeficientas.

\section{REZULTATAI}

Atlikus tyrimus, gauti tokie rezultatai:

BE-50 ir BE-25 grupių berniukų šuolių aukštis padidèjo (per 15 pratybų) statistiškai reikšmingai $(p<0,05)(1$ ir 2 pav. $)$

BE-50 grupès šuolio aukščio rezultatas pagerèjo reikšmingai $(\mathrm{p}<0,05)$ daugiau nei $\mathrm{BE}-25$ (2 pav.).

Bendras kontrolinès grupės pirmų pratybų po 2 mėnesių rezultatų vidurkis beveik nepakito (3 pav.).
1 pav. Berniukų šuolių rezultatų vidurkio kaita

Pastaba. BE-25 - berniuku eksperimentinè grupè, atlikusi po 25 šuolius per kiekvienas pratybas; BE-50 — berniukų eksperimentinè grupè, atlikusi po 50 šuolių per kiekvienas pratybas. $*-\mathrm{p}<0,05$.

2 pav. Berniukų šuolių rezultatų vidurkio procentinè kaita

Pastaba. BE-25 - berniukų eksperimentinè grupè, atlikusi po 25 šuolius per kiekvienas pratybas; BE-50 — berniukų eksperimentinè grupé, atlikusi po 50 šuolių per kiekvienas pratybas.
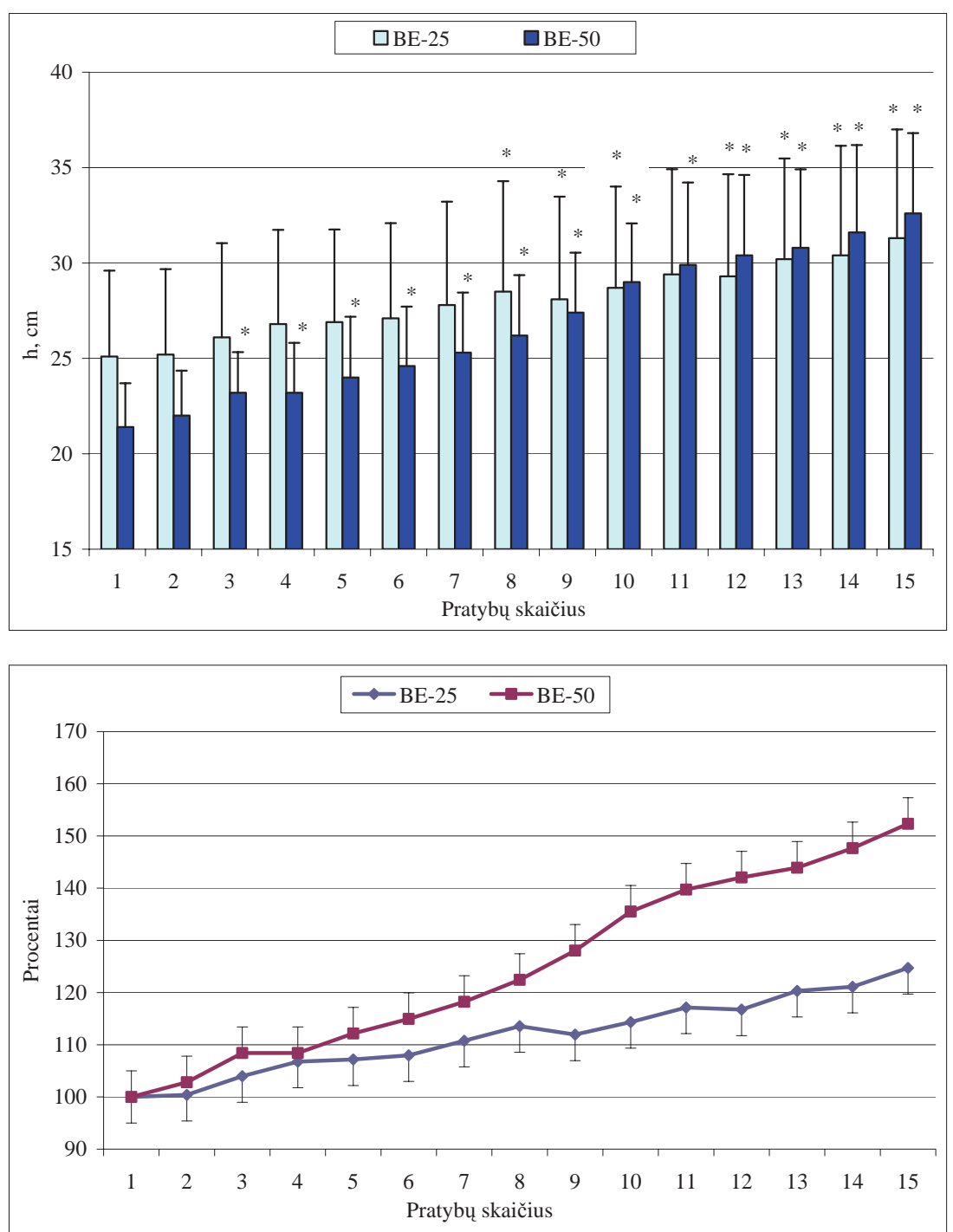

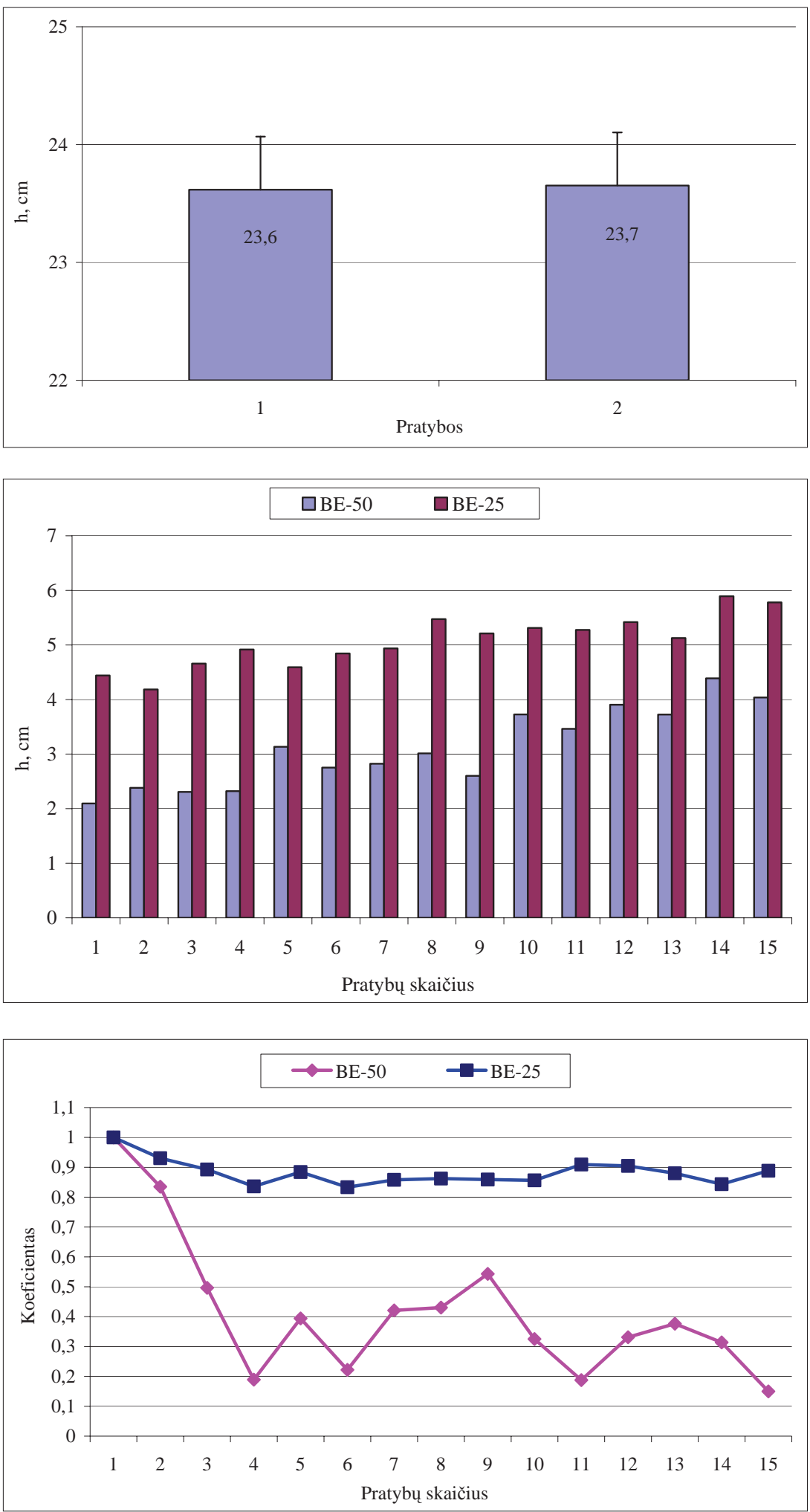

3 pav. Kontrolinės grupès (BK-25) berniukų vertikalių šuolių aukščio rezultatu vidurkiai prieš 2 mẻnesius ir po jų

4 pav. Berniukų šuolių rezultatų vidurkio procentinè kaita

Pastaba. BE-25 — berniuku eksperimentinè grupè, atlikusi po 25 šuolius per kiekvienas pratybas; BE-50 — berniuku eksperimentinè grupè, atlikusi po 50 šuoliu per kiekvienas pratybas.

5 pav. Berniuku vertikaliu šuoliu rezultatų koreliacijos koeficientų sklaida, lyginant su pirmomis pratybomis

Pastaba. BE-25 - berniukų eksperimentinè grupè, atlikusi po 25 šuolius per kiekvienas pratybas; BE-50 - berniuku eksperimentinè grupè, atlikusi po 50 šuoliu per kiekvienas pratybas.
Bendra berniukų vertikalių šuolių vidurkio rezultatų sklaida po pratybų padidèjo. Didesnè rezultatų sklaida pastebima tarp berniukų, atlikusiu daugiau šuoliu (BE-50 grupès).

Moksleiviu, atlikusių po 50 šuoliu per pratybas, koreliacijos koeficientas, lyginant su pirmomis pratybomis ir esant tiesioginei priklausomybei, krinta banguotai (5 pav.). Per paskutines pratybas tas ryšys pasidaro labai silpnas. Vadinasi, pagal pirmų pratybų rezultatus negalima prognozuoti galutinių.

Tarp berniukų, atlikusių po 25 šuolius per kiekvienas pratybas, rezultatu, lyginant su pirmomis ir esant tiesioginei priklausomybei, pastebimas nuolatinis stiprus koreliacinis ryšys. 


\section{REZULTATŲ APTARIMAS}

Aštuonių savaičių trukmès vertikalių šuolių krūviai reikšmingai padidina šoklumą. Sporto pedagogai ir mokslininkai, tiriantys šoklumo ugdymo priemonių ir metodų veiksminguma, pastebi, kad ugdant šoklumą pagerejja greitumo ir raumenu galingumo rodikliai. Ketvirtų klasių berniuku rezultatai parodè, kad tiek tyrimo pradžioje, tiek pabaigoje vertikalaus šuolio aukštis visų vaikų yra skirtingas. Šuolio aukštį lemia labai daug veiksnių. Maždaug trečiais gyvenimo metais susiformuoja pagrindiniai šuolių atlikimo motorinès programos bruožai, o tolesniais ontogenezès tarpsniais ji tik tobulejja. Tačiau motorinè programa, kaip ir kiti refleksiniai bei raumeniniai mechanizmai, gali būti modifikuojami priklausomai nuo šuolio būdo, mokejjimo ji atlikti ir susikaupimo laipsnio (Schmidt, 1988; Komi, 1992; Jeannerod, 1994). Šuolio amortizuojamai pritūpiant (hp 90) aukštis priklauso nuo gebejjimo panaudoti elastinę raumenų energiją ir tempimo refleksa. Toks gebejjimas priklauso nuo raumenu kompozicijos — greiti sportininkai geriau panaudoja elastinę energiją greitai ir lengvai amortizuojamai pritūpdami, o lèti — lètai ir smarkiai pritūpdami (Komi, 1992). Taigi aiškinantis vaikų šoklumo skirtumus būtina atsižvelgti į registruojamo šoklumo rodiklio specifika, nes vienu šoklumas labiau priklauso nuo genetiniu veiksniu, kitų — nuo ugdymo pobūdžio. Nors netyrème raumenų kompozicijos, manytume, kad šoklesni yra tie vaikai, kurių raumenyse vyrauja greitosios RS, arba iš prigimties stipresni vaikai. Tai patvirtina ir kiti autoriai (Jaščaninas ir kt., 1989; Hakkinen, 1994). Puberteto metu vaikų fizinis parengtumas labai priklauso nuo biologinio brendimo laipsnio (Malina, Bouchard, 1991). Testosterono kiekis kraujo plazmoje koreliuoja su raumenų maksimaliaja jèga (Kraemer, Feck, 1993), o pubertatiniu laikotarpiu kaip tik daugeja testosterono (Malina, Bouchard, 1991 ir kt.), ir tai skatina raumenų jègos augimą bei lavejjimą. Atlikto tyrimo metu nebuvo matuojamas testosterono kiekis kraujyje, tačiau tai, kad to paties pasinio amžiaus vaikų biologinis amžius buvo panašus, leidžia teigti, kad šis veiksnys negali būti svarbiausias vertinant vaikų šoklumo rodiklių skirtumą. Tačiau su augimu ir lytiniu brendimu susiję motorikos ugdymo ypatumai gali labai veikti tiriamujų šoklumo kaitą.

Manytume, berniukų šoklumą, lyginant su pirmaisiais rezultatais, reikšmingai pagerino reguliarūs šoklumą ugdantys krūviai (Kamandulis, Skurvydas, 2003), o šuolių rezultatai dèl treniruočių nuolatos gerèjo dèl to, kad geriau išmokta atlikti judesi — šuoli (Takahashi et al., 2006). Kaip matyti iš tyrimo rezultatu, visų tiriamuju vertikalaus šuolio rezultatai buvo reikšmingai pagerinti. Tai dar kartą patvirtina (Balsom et al., 1992; Glenmark et al., 1992; Kommi, 1992) organizmo adaptacijos prie fizinių krūvių dėsningumus.

Skirtumas tarp silpniausiai ir geriausiai šokančiuju rezultatu dar labiau išaugo, manytume, dèl daugelio veiksnių, lemiančių skirtingą jaunesniojo mokyklinio amžiaus berniukų reakciją $i$ mūsų teiktą fizini krūvị. Taigi jie priklauso nuo: psichologiniu veiksniu, t. y. kaip moksleivis geba reikiamai susikaupti, ar turi motyvacija; motorinès programos sudarymo tikslumo - nuo jo priklauso agonistų, sinergetų, antagonistu, rankų ir kojų raumenų koordinacija, kuri padeda geriau atlikti šuoli (Schmidt, 1988; Skurvydas ir kt., 1988; Skurvydas, Mamkus, 1990); raumenų kompozicijos kuo daugiau raumenyse yra greitai susitraukiančiu raumeninių skaidulu, tuo geresnis tiriamuju šoklumas (Hakkinen, 1994; Janutis, Grūnovas, 2004); raumenų susitraukimo ilgio; greitujų raumeninių skaidulų hipertrofijos (Goldspink, 1992; Enoka, 1994); raumenu ir sausgysliu elastingumo (Bosco et al., 1983, 1984); raumeniniu sausgysliu prisitvirtinimo kampo (Enoka, 1994).

Aštuonių savaičių trukmės vertikalaus šuolio aukštyn krūviai reikšmingai padidina šoklumą, tačiau iš pradinių rezultatų negalima nustatyti, prognozuoti galutinių.

\section{IŠVADOS}

1. Abiejų grupių berniukų šoklumas dèl nuoseklių pratybu reikšmingai pagerèjo, lyginant su pirmujų rezultatais.

2. Tyrimu nustatyta, kad dvigubai didesnis fizinis krūvis lemia ir du kartus geresnius vertikalaus šuolio rezultatus. Du mėnesius ugdant jaunesniojo mokyklinio amžiaus berniukų šoklumą, grupès, kuri atliko dvigubai daugiau šuolių (750), rezultatai buvo geresni 50\% nei atlikusios 375 šuolius. Didesnis fizinis krūvis geriau lavina berniukų šokluma.

3. Berniukų bendro vertikalių šuolių rezultatų vidurkio sklaida dèl pratybų padidèjo. Berniukų, atlikusių daugiau šuoliu, rezultatų sklaida didesnè.

4. Iš pirmų pratybų vertikalių šuolių rezultatų negalima prognozuoti galutinių. 


\section{LITERATŪRA}

Astrand, P. O., Rodahl, K. (1986). Textbook of Work Physiology: Physiological Bases of Exercise. McGraw-Hill.

Balsom, P. D., Seger, J. Y., Sjodin, B., Ekblom, B. (1992) Physiological responses to maximal intensity intermittent exercise. European Journal of Applied Physiology, 65, 144-149.

Belanger, A. Y., McComas, A. J. (1989). Contractile properties of human skeletal muscle in childhood and adolescence. European Journal of Applied Physiology, 58, 563-567.

Bobbert, M. F. (1990). Drop jumping as a training method for jumping ability. Sports Medicine, 9 (1), 7-22.

Booth, F. W., Thomason, D. B. (1991). Molecular and cellular adaptation of muscle in response to exercise: Perspectives of various models. Physiological Review, 71 (2), 541-585.

Bosco, C., Komi, P. (1979). Mechanical characteristics and fiber composition of human leg extensors muscles. European Journal of Applied Physiology, 41, 275-284.

Bosco, C., Komi, P. V., Tihanyi, J., Fekete, G., Apor, P. (1983 a). Mechanical power test and fiber composition of human leg extensor muscles. European Journal of Applied Physiology, 51 (1), 129-135.

Bosco, C., Luhtanen, P., Komi, P. V. (1983 b). A simple method for measurement of mechanical power in jumping. European Journal of Applied Physiology, 50 (2), $273-282$

Bosco, C., Zanon, S., Rusko, H., Dal Monte, A. et al. (1984). The influence of extra load on the mechanical behavior of skeletal muscle. European Journal of Applied Physiology, 5 (2), 149-154.

Enoka, R. M., Stuart, D. G. (1992). Neurobiology of muscle fatigue. Journal of Applied Physiology, 72, 16311648.

Fitts, R. H., McDonald, K. S., Schluter, J. M. (1991). The determinants of skeletal muscle force and power: Their adaptability with changes in activity pattern. Journal of Biomechanics, 1, 111-122.

Glenmark, B., Hedberg, G., Jansson, E. (1992). Changes in muscle fiber type from adolescence tu adulthood in women and men. Acta Physiologica Scandinavica, 146, $251-259$

Goldspink, G. (1992). Cellular and Molecular Aspects of Adaptation in Skeletal Muscle. Oxford. P. 211-230.

Hakkinen, K. (1994). Neuromuscular adaptation during strength training, aging, detraining and immobilization. Critical Review in Physical and Rehabilitation Medicine, 6 (3), 161-198.

Janutis N., Grūnovas, A. (2004). Sportininkų, adaptuotų fiziniams krūviams, raumenu darbingumo ivertinimas. Ugdymas. Kūno kultūra. Sportas, 1 (51), 24-29.

Jaščaninas, J., Skurvydas, A., Mamkus, G., Ratkevičius, A. (1989). Ivairaus kryptingumo treniruočių krūviai, raumens susitraukimo greičio jëgos ypatybės ontogenezè ir sportinès atrankos aspektai. Sveikatos apsauga, 6, 24-29.

Jeannerod, M. (1994). The timing of natural apprehension. Journal of Motor Behavior, 16, 201-211.

Karoblis, P. (1999). Sporto treniruotés teorija ir didaktika. Vilnius.
Komi, P. V. (1992). Strength and Power in Sport. Oxford.

Korman, M., Raz, N., Flash, T., Karni, A. (2003). Multiple shifts in the representation of a motor sequence during the acquisition of skilled performance. PNAS: Neuroscience, 100 (21), 12492 - 12497.

Kraemer, W. J., Fleck, S. J. (1993). Strength Training for Young Athletes. Champaign, IL: Human Kinetics.

Malina, R. M., Bouchard, C. (1991). Growth, Maturation and Physical Activity. Champaigin, IL: Human Kinetics.

Mamkus, G. (1998). Amžiaus ir treniruotès poveikis koju raumenu susitraukimo ir atsipalaidavimo savybems: daktaro disertacijos santrauka. Kaunas: LKKI.

McDonagh, M., Davies, C. (1984). Adaptive response of mammalian skeletal muscle to exercise with loads. European Journal of Applied Physiology, 52, 139-155.

Salmons, S. (1994). Exercise, stimulation and type transformation of skeletal muscle. International Journal of Sports Medicine, 15 (5), 136-141.

Schmidt, R. A. (1988). Motor Control and Motor Learning. Champaign, IL: Human Kinetics.

Skurvydas, A., Jaščianinas, J., Buliuolis, A., Gedvilas, V. (1995). Griaučių raumenų susitraukimo nuovargio bei atsigavimo ypatumai kintant amžiui. Ugdymas. Kūno kultūra. Sportas, 28, 54-62.

Skurvydas, A., Mamkus, G. (1990). Sportininku perspektyvumo nustatymas remiantis raumenu kompozicija. Vilnius.

Skurvydas, A. (1991). Organizmo adaptacijos prie fiziniu krūviu pagrindiniai désningumai. Vilnius: Sporto metodikos kabinetas.

Skurvydas, A., Stasiulis, A., Vilčinskas, P. (1988). Šoklumo fiziologiniai pagrindai. Vilnius.

Spirduso, W. W. (1995). Physical Dimensions of Ageing. Human Kinetics.

Stanislovaitis, A. (1998). Influence of specialized strength, sprint and endurance training loads on adaptation characteristics of the function of human skeletal muscles: Summary of doctoral dissertation. Kaunas: LKKI.

Takhashi, C. D., Nemet, D., Rose-Gottron, C. M. et al. (2006). Effect of muscle fatigue on internal model formation and retention during reaching with the arm. Journal of Applied Physiology, 100, 695-706.

Viitasalo, J. T., Salo, A., Lahtinen, J. (1998). Neuromuscular functioning of athletes and non-athletes in the drop jump. European Journal of Applied Physiology, 78 (5), 432-440.

Wilmore, J. H., Costill, D. L. (1994). Physiology of Exercise and Sport. Champaign, IL: Human Kinetics. 


\title{
SPRING DYNAMICS OF THE JUNIOR SCHOOL AGE BOYS
}

\author{
Eduardas Rudas ${ }^{1}$, Albertas Skurvydas ${ }^{1}$, Dalia Mickevičiené ${ }^{1}$, \\ Vaidas Mickevičius ${ }^{2}$, Tomas Juraitis ${ }^{1}$ \\ Lithuanian Academy of Physical Education1, Kaunas Technical College2, Kaunas, Lithuania
}

\begin{abstract}
The aim of the research was to establish and compare the spring dynamics of the junior school age boys while developing their spring techniques for two months applying different loads.

In this article we compared the spring dynamics of healthy school age children of normal constitution aged 9-11 years developing their spring techniques with different loads for eight weeks. The research participants were 49 boys of the fourth forms. The study included two experimental and one control group. The experimental groups involved 32 schoolboys, 16 boys in each group. The mean age of the boys $(\mathrm{n}=16)$ in the first experimental group was $10.0 \pm 0.7$ years, their body mass was $34.8 \pm 6.7 \mathrm{~kg}$, and their height was $143.6 \pm 7.2 \mathrm{~cm}$. In the second experimental group $(\mathrm{n}=16)$ the mean age was $10.3 \pm 0.4$ years, the body mass $-34.8 \pm 6.7 \mathrm{~kg}$, and their height $-143.6 \pm 7.2 \mathrm{~cm}$. In the control group $(\mathrm{n}=17)$ the mean age of the research participants was $10.4 \pm 0.5$ years, the body mass $-34.8 \pm 6.8 \mathrm{~kg}$, and the height $-145.1 \pm 6.8 \mathrm{~cm}$. Three studies were performed.

In the experimental groups the spring techniques of the research participants were developed in 15 training sessions which lasted for two months two times a week. The control group was tested twice - at the beginning of the experiment and after eight weeks. During each training session in the experimental groups the boys performed maximal vertical jumps after a ten-minute warm-up. In the first experimental group the research participants performed 50 jumps every 30 seconds in each training session. In the second experimental group 25 maximal vertical jumps were performed every $30 \mathrm{~s}$ in each training session after the same warm-up. In the control group the boys performed 25 vertical jumps every $30 \mathrm{~s}$. In all the three groups the boys were recommended to jump as high as possible. For the assessment of the jump height we used the contact platform connected to the electronic jump height and take-off time measuring device. The vertical jumps were performed with amortization squats with the knees bent $90^{\circ}$ (the angle was controlled observing the jumps), hands on the waist. The jump results were recorded in the personal jump protocols. The research results were processed applying the methods of mathematical statistics.

The research results indicated that spring techniques of the boys in both experimental groups significantly improved; however, the jump improvement results of boys who performed more jumps were statistically significantly higher $(\mathrm{p}<0.05)$ than those of the boys who performed fewer jumps. The differences in the jump results of the boys in the control group were not significant. Due to the training sessions the dispersion of the mean spring results of schoolboys significantly increased in the group where more jumps were performed. Besides, we established that there was no significant correlation between the jump height at the beginning of training and at the end (after 15 training sessions).
\end{abstract}

Keywords: jumps, spring techniques, muscle fatigue.

Gauta 2009 m. sausio 27 d.

Received on January 27, 2009

Eduardas Rudas

Lietuvos kūno kultūros akademija

(Lithuanian Academy of Physical Education)

Sporto g. 6, LT-44221 Kaunas

Lietuva (Lithuania)

Tel +3702701431

E-mail e.rudas@lkka.lt 